\title{
Article
}

\section{Infrared Absorption Detection of Metal Ion-Deoxyguanosine Monophosphate Binding: Experimental and Theoretical Study \\ Valery Andrushchenko, and Petr Bour\#}

J. Phys. Chem. B, 2009, 113 (1), 283-291 • DOI: 10.1021/jp8058678 • Publication Date (Web): 08 December 2008

Downloaded from http://pubs.acs.org on January 30, 2009

\section{More About This Article}

Additional resources and features associated with this article are available within the HTML version:

- Supporting Information

- $\quad$ Access to high resolution figures

- $\quad$ Links to articles and content related to this article

- Copyright permission to reproduce figures and/or text from this article

\section{View the Full Text HTML}




\title{
Infrared Absorption Detection of Metal Ion-Deoxyguanosine Monophosphate Binding: Experimental and Theoretical Study
}

\author{
Valery Andrushchenko* and Petr Bouř* \\ Institute of Organic Chemistry and Biochemistry, Academy of Sciences of the Czech Republic, Flemingovo \\ nám. 2, 16610, Praha 6, Czech Republic
}

Received: July 3, 2008; Revised Manuscript Received: October 19, 2008

\begin{abstract}
Metal ion interactions with nucleic acids attract attention because of the environmental and biological consequences. The formation of the complex is often monitored by the vibrational spectroscopy. To identify characteristic binding patterns and marker bands on a model DNA component, infrared absorption spectra of the deoxyguanosine monophosphate complexes with $\mathrm{Na}^{+}, \mathrm{Mg}^{2+}, \mathrm{Ca}^{2+}, \mathrm{Ni}^{2+}, \mathrm{Cu}^{2+}, \mathrm{Zn}^{2+}$, and $\mathrm{Cd}^{2+}$ cations were recorded and interpreted on the basis of density-functional computations. The aqueous environment was simulated by continuum and combined continuum-explicit solvent models. For the binding to the N7 position of the guanine base, the computation predicted a characteristic frequency upshift and splitting of the $1578 \mathrm{~cm}^{-1}$ band, which is in accord with available experimental data. Contrary to the expectation, the modeling suggests that the binding to the carbonyl group might not be detectable, as the metal causes smaller spectral changes if compared to the hydrogen-bound water molecules. The binding to the phosphate group causes significant spectral changes in the sugar-phosphate vibrating region $\left(\sim 800-1200 \mathrm{~cm}^{-1}\right)$, but also notable frequency shifts of the carbonyl vibrations. The $\mathrm{Cu}^{2+}$ and $\mathrm{Zn}^{2+}$ ions induced the largest alterations in observed vibrational absorption, which corresponds to the calculated strong interaction energies in the N7-complexes and to previous experimental experience. Additional changes in the vibrational spectra of the copper complexes were observed under high metal concentration, corresponding to the simultaneous binding to the phosphate residue. The two-step $\mathrm{Cu}^{2+}$ binding process was also confirmed by the microcalorimetry titration curve. The computations and combination of more techniques thus help us to assign and localize spectral changes caused by the metal ion binding to nucleic acids.
\end{abstract}

\section{Introduction}

Complexes of metal ions with nucleic acids participate in various biological processes, such as DNA replication and transcription, enzymatic cleavages, mutagenesis, carcinogenesis, and DNA packing in a living cell and also stabilize particular nucleic acid secondary structures. ${ }^{1-6}$ A vast number of experimental and theoretical studies have been dedicated to metal interactions with nucleic acids and their components. ${ }^{5-10}$ In the present work we systematically investigate interactions of some common metal ions with deoxyguanosine monophosphate (dGMP) as a model system, in order to better explain previously observed changes in infrared absorption (IR) spectra of nucleic acids upon the interaction with the metals.

Being relatively simple and widely available, infrared spectroscopy provided precious information about the interaction of metal ions with nucleic acids (e.g., see refs 11-23). Detailed structural information could be obtained from the IR spectra when observed bands were assigned to particular bonds or DNA functional groups. ${ }^{24-27}$ In practice, however, the assignment is complicated by solvent interference, overlapped and naturally broad vibrational bands, and coupling of vibrations in different groups.

The spectral interpretation can be significantly simplified if the experimental shapes are directly compared to those simulated by the techniques of quantum chemistry. ${ }^{28-31}$ In the past, such computations provided preferential geometries and binding sites and could explain different DNA affinity to different metals. ${ }^{32-34}$

* To whom correspondence should be addressed; E-mail: bour@ uochb.cas.cz (P.B.); vandrush@uochb.cas.cz (V.A.).
Because of the computational limits, the modeling is often restricted to simplified nucleic acid components. This approach was proven to be very successful, although the preceding studies mostly concentrated on the geometry and energetics, ${ }^{10,32-40}$ whereas the vibrational analysis can be encountered less frequently. ${ }^{36}$ Particularly for the nucleotide-metal ion complexes, we are not aware of any direct comparison of the computed and experimental IR data pursued in the present study.

Another aspect that we want to address is the proper account for the solvent, often ignored in the previous studies. Although it may not be essential for evaluation of relative energies associated with some nonelectrostatic metal-nucleobase interactions, ${ }^{32}$ a proper solvent model is crucial for the estimation of the vibrational frequencies, particularly for vibrations of the polar groups of the nucleic acids. ${ }^{28}$ Typically, polarized continuum models (PCM) are used in such studies, which can be implemented very efficiently in available computational codes. ${ }^{41,42}$

Ultimately, we test the preferred and specific binding sites of the dGMP molecule (Figure 1) for different metal ions. It is generally accepted that alkaline metal ions $\left(\mathrm{Li}^{+}, \mathrm{Na}^{+}, \mathrm{K}^{+}, \mathrm{Rb}^{+}\right.$, and $\mathrm{Cs}^{+}$) prefer interaction with the phosphate groups, forming a counterion shell around the negatively charged DNA helix. ${ }^{6}$ Alkaline earth metal ions $\left(\mathrm{Ca}^{2+}, \mathrm{Mg}^{2+}, \mathrm{Sr}^{2+}\right.$, and $\left.\mathrm{Ba}^{2+}\right)$ also exhibit a higher affinity for the phosphate, but they can also bind to the aromatic base. Transition metal ions $\mathrm{Mn}^{2+}, \mathrm{Cu}^{2+}$, $\mathrm{Ni}^{2+}, \mathrm{Co}^{2+}, \mathrm{Zn}^{2+}, \mathrm{Cd}^{2+}$, etc.) bind well to both sites. Their affinity to the base approximately increases as $\mathrm{Co}^{2+} \sim \mathrm{Ni}^{2+}<$ $\mathrm{Zn}^{2+}<\mathrm{Mn}^{2+}<\mathrm{Cd}^{2+}<\mathrm{Cu}^{2+}$. 


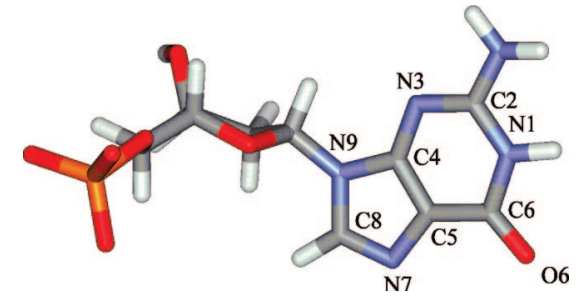

Figure 1. The deoxyguanosine monophosphate (dGMP) and atomic numbering in the purine ring of the guanine.

Because the binding to the $\mathrm{N} 3$ atom is sterically restricted by the sugar moiety attached at the $\mathrm{N} 9$ position in the purine nucleotides, ${ }^{9}$ the N7 is generally considered as the dominant binding site. ${ }^{7}$ The $\mathrm{N} 7$ nitrogen is also thought to be a better ligand than the O6 oxygen of guanine $(\mathrm{G})$, although simultaneous coordination to N7 and O6 was excluded. ${ }^{7,43}$ Likewise, a direct coordination of a metal ion to N7 and the phosphate group of the same nucleotide has not been observed. ${ }^{9}$ However, participation of multiple binding sites mediated by water bridges is possible. Both experimental and theoretical data show that O6 and phosphate oxygens can indirectly bind to the hydration shell of the metal ion, which is directly coordinated to N7. 9,32,36,43,44 The present results confirm the various modes of the binding but suggest that the relation between the spectral changes and different binding patterns is more complex than previously thought.

\section{Materials and Methods}

Experimental. Guanosine 5'-monophosphate disodium salt (dGMP) (99\% purity) was purchased from Fluka Biochemica; metal chlorides and $\mathrm{D}_{2} \mathrm{O}$ (99\% purity, ACS grade) were obtained from Sigma-Aldrich. All solutions were prepared in heavy water to avoid interference of the $\mathrm{H}_{2} \mathrm{O}$ bending vibration with the dGMP carbonyl and base ring IR bands. The samples were dissolved in $\mathrm{D}_{2} \mathrm{O}$, lyophilized, and redissolved again to ensure a complete hydrogen-deuterium exchange. The dGMP and metal ion solutions were mixed before the measurements. For some samples a light opalescence appeared after the mixing. It was probably caused by a limited solubility of the complexes, but the samples and their IR absorption were stable during the time needed for the spectral measurement. The $\mathrm{pH}$ of the samples was in the range of 7.0-7.5. The final concentration of dGMP in the spectroscopic cell was $10 \mathrm{mg} / \mathrm{mL}(24.5 \mathrm{mM})$. For all salts except $\mathrm{Na}^{+}$, two metal/dGMP molar ratios were used, 1:1 and 20:1. For sodium, already present in the disodium salt of dGMP, only the higher ratio 20:1 was prepared. Concentrations of dGMP and metal salts were calculated from weights of dry compounds.

The absorption spectra were acquired with the Equinox 55 FTIR spectrophotometer (Bruker Optics, Inc.) using a $\mathrm{BaF}_{2}$ cell with path length of $35 \mu \mathrm{m}$, at room temperature $\left(\sim 22^{\circ} \mathrm{C}\right)$. The path length was determined by counting the number of interference fringes measured with empty cell. As the background spectrum, $\mathrm{D}_{2} \mathrm{O}$ was used for free dGMP, whereas spectra of metal solutions in $\mathrm{D}_{2} \mathrm{O}$ were used for the complexes to account for the influence of the metal salt on water spectrum. ${ }^{45}$ The spectral manipulations were done with the Opus software (Bruker Optics, Inc.). Raman spectrum of free dGMP (not shown) was acquired using analogous conditions as for IR with a multipurpose spectrometer ${ }^{46}$ located at the Charles University, Prague. By comparison of computed and experimental Raman intensities, IR assignments of vibrational transitions could be independently verified.
For the copper-dGMP interaction, isothermal titration calorimetry (ITC) was carried out on a VP-ITC calorimeter (MicroCal, Northampton, MA, USA). The $\mathrm{CuCl}_{2}$ solution loaded in the syringe was injected into dGMP solution $(2.45 \mathrm{mM}$, at $25^{\circ} \mathrm{C}$ ) in the calorimeter cell in aliquots of $10 \mu \mathrm{L}$ with $360 \mathrm{~s}$ intervals between the individual injections. The calorimeter reference cell contained MilliQ water. All solutions were thoroughly degassed before the titration. To account for the heat of the salt dilution, a control experiment was completed by titrating $\mathrm{CuCl}_{2}$ into water instead of the dGMP solution. The total observed heats of binding were adjusted for the heat of $\mathrm{CuCl}_{2}$ dilution. The heat of dGMP dilution was negligible. All data processing was performed with the MicroCal Origin software supplied with the calorimeter. The titration curve could not be fitted by a single-site model supplied with the Origin and we did not perform a custom fit. However, the two-stage character of the titration curve supported the binding pattern observed in the IR spectra.

Computations. Initial dGMP geometry was generated by the Biosym software, ${ }^{47}$ providing a standard DNA conformation. Alternatively, X-ray dGMP geometry from the CrystalQuest database was used, ${ }^{48}$ which, however, had no significant influence on the final results. For the complexes, each metal ion was initially placed at $\sim 2 \AA$ from the N7 atom in the base plane, or at $\sim 2 \AA$ from one of the phosphate oxygens in the direction from the base. Such a position of the ions with respect to the phosphate group represents one of many possibilities, allowing us to estimate main effects of the metal complexation on the phosphate group vibrations. A direction to the base was not considered in order to separate the N7 and phosphate binding effects. For the $\mathrm{Cu}^{2+}$ ion, an N3 complex was also created in a similar manner. In addition, pentahydrated metal complexes with metals bound to the N7 and O6 sites of the guanine base (without the sugar-phosphate residue) were created as derived from regular octahedral water coordination around the metal ion. The initial structures were optimized by an energy minimization using the GAUSSIAN program ${ }^{42}$ and the Becke3LYP functional $^{49}$ with the $6-31+\mathrm{G}^{* *}$ Pople-type basis set. The LANL2DZ relativistic pseudopotential and basis ${ }^{50}$ were used for the cadmium atom. The solvent was modeled by the GAUSSIAN version (CPCM) of the $\mathrm{COSMO}^{41}$ conductor-like continuum correction. For the optimized structures, the harmonic vibrational frequencies and IR intensities were calculated by GAUSSIAN. For the hydrated complexes, the initial structures were preoptimized by the Turbomole $\operatorname{program}^{51}$ (at the same Becke3LYP/6-31+G** level). Turbomole provided faster and more numerically stable optimizations, whereas it was more efficient to revert to GAUSSIAN for the final optimization and frequency calculations.

Electronic interaction energies for the dGMP-metal complexes were calculated as a difference between the energy of the complex and energies of the monomers $\Delta E^{\mathrm{int}}=E^{\mathrm{dGMP}-\mathrm{M}}-$ $\left(E^{\mathrm{dGMP}}+E^{\mathrm{M}}\right)$, where $E^{\mathrm{dGMP}-\mathrm{M}}, E^{\mathrm{dGMP}}$, and $E^{\mathrm{M}}$ are the energies of the dGMP-metal ion complex, dGMP alone, and the metal ion alone, respectively. Similarly, interaction energies of the hydrated metal ions were estimated as $\Delta E^{\mathrm{int}}=\left(E^{\mathrm{G}-\mathrm{M}-5 \mathrm{~W}}+E^{\mathrm{W}}\right)$ - $\left(\mathrm{E}^{\mathrm{G}}+\mathrm{E}^{\mathrm{M}-6 \mathrm{~W}}\right)$, where $E^{\mathrm{G}-\mathrm{M}-5 \mathrm{~W}}, E^{\mathrm{W}}, E^{\mathrm{G}}, E^{\mathrm{M}-6 \mathrm{~W}}$ are the respective energies of the guanine-pentahydrated metal ion complex, single water molecule, guanine base, and the hexahydrated metal ion. It should be noted that the $\mathrm{Cd}^{2+}$ ion interaction energies obtained with the LANL2DZ relativistic pseudopotential and basis are de facto computed on a different level than the Becke3LYP/6-31+G** approximation used for the other metal ions. However, for the purpose of this study, we consider 

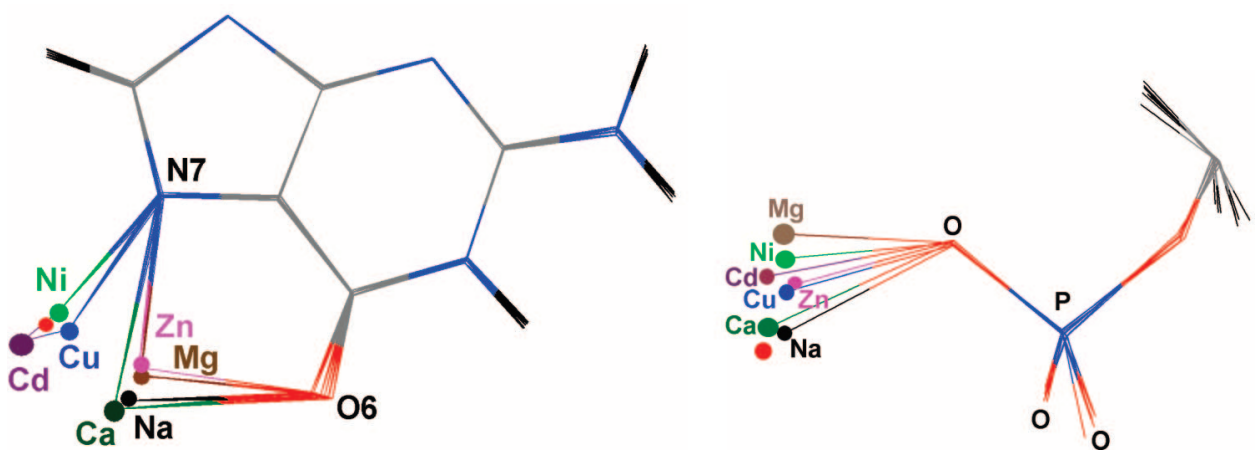

Figure 2. Initial (red circle) and optimized (B3LYP/CPCM/6-31+G**, color circles) positions of the metals in the complex with dGMP bound to the guanine base (left) and the phosphate group (right).

TABLE 1: Calculated (B3LYP/CPCM/6-31+G**) Selected Distances ${ }^{a}(d$, in $\AA$ ) and Relative Binding Energies $(E, \mathrm{kcal} / \mathrm{mol})$ for the Bare Metal Ions Interacting with the dGMP

\begin{tabular}{|c|c|c|c|c|c|c|c|}
\hline metal & $d(\mathrm{~N} 7-\mathrm{M})$ & $d(\mathrm{O} 6-\mathrm{M})$ & $d(\mathrm{C}=\mathrm{O} 6)$ & $d(\mathrm{PO}-\mathrm{M})$ & $d(\mathrm{P}=\mathrm{O})$ & $E_{\text {base }}^{b}$ & $E_{\mathrm{PO}}^{b}$ \\
\hline none & & & $1.243(1.194)$ & & $1.547 / 1.547 / 1.544$ & & \\
\hline $\mathrm{Na}^{+}$ & $2.43(2.41)$ & $2.31(2.26)$ & $1.258(1.219)$ & 2.13 & $1.563 / 1.540 / 1.537$ & 3 & 9 \\
\hline $\mathrm{Mg}^{2+}$ & $2.11(2.06)$ & $2.03(1.94)$ & $1.277(1.262)$ & 1.84 & $1.600 / 1.525 / 1.521$ & 44 & 28 \\
\hline $\mathrm{Cd}^{2+}$ & $2.36(2.24)$ & $3.71(2.18)$ & $1.239(1.258)$ & 2.08 & $1.607 / 1.526 / 1.523$ & 7 & 61 \\
\hline $\mathrm{Zn}^{2+}$ & $2.02(1.98)$ & $2.04(1.91)$ & $1.281(1.267)$ & 1.80 & $1.643 / 1.518 / 1.515$ & -7 & 25 \\
\hline $\mathrm{Zn}^{2+c}$ & 1.95 & 3.28 & 1.254 & & & 32 & \\
\hline $\mathrm{Cu}^{2+}$ & $1.91(2.15)$ & $3.14(2.18)$ & $1.240(1.222)$ & 1.86 & $1.548 / 1.549 / 1.543$ & -109 & -95 \\
\hline
\end{tabular}

${ }^{a}$ The numbers in the parentheses were obtained for a vacuum calculation from ref 35 . Three numbers for the $\mathrm{P}=\mathrm{O}$ distances refer to the three $\mathrm{P}=\mathrm{O}$ bonds. ${ }^{b}$ Binding to the guanine base $\left(E_{\text {base }}\right)$ and phosphate group $\left(E_{\mathrm{PO}}\right) .{ }^{c}$ Explicit water molecule between $\mathrm{Zn}$ and O6. ${ }^{d}$ Explicit water molecule between $\mathrm{Zn}$ and $\mathrm{N} 7$.

them to be comparable, as the relativistic effects have a minor influence on the valence electrons and mostly subtract for the interaction energies. All lighter atoms were also treated at the Becke3LYP/6-31+G** level in the cadmium complexes. Zeropoint vibrational correction was added to the electronic energies. As noted before, although such interaction energies corresponding to the zero temperature and the gas phase cannot be directly compared to the experimental enthalpies, they usually describe well the relative stabilities of the complexes and the binding affinities of metal ions. ${ }^{33}$

\section{Results and Discussion}

Geometries and Energies. Optimized structures of the dGMP-metal ion complexes with the PCM solvent correction can be seen in Figure 2; the distances from the N7, O6, and $\mathrm{O}(\mathrm{P})$ binding sites, the $\mathrm{C}=\mathrm{O}$ and $\mathrm{P}=\mathrm{O}$ bond lengths and binding energies are also summarized in Table 1. The metals can be divided into two groups according to their behavior. Optimized positions of $\mathrm{Cu}^{2+}, \mathrm{Cd}^{2+}$, and $\mathrm{Ni}^{2+}$ are closer to $\mathrm{N} 7$, whereas the metals of the second group $\left(\mathrm{Na}^{+}, \mathrm{Ca}^{2+}, \mathrm{Mg}^{2+}\right.$, and $\left.\mathrm{Zn}^{2+}\right)$ moved closer to the carbonyl oxygen. Metals that form strong coordination bonds with participation of the d-orbitals thus prefer the nitrogen binding site. The zinc ion can be considered as an intermediate between the light alkaline earth metals and the electron-rich transition metals, although it shows more favorable binding to the guanine ring than the heavier cadmium ion (Table 1). The ionic charge, the same for all metals except sodium, seems to play a minor role in the binding site preference. The origin of the binding modes in the fine electronic structure was also discussed previously by Šponer and co-workers. ${ }^{33,38,39}$

The geometrical parameters obtained with the dielectric solvent model are in a qualitative agreement with the previous vacuum computations by Burda and co-workers, also listed in
Table $1 .^{35}$ However, the solvent correction clearly causes systematic geometry changes and large energy differences; thus, it should not be omitted in a more reliable modeling. The relative binding energies indicate that the $\mathrm{Cu}^{2+}$ ion is the strongest guanine-binding ligand, followed by $\mathrm{Ni}^{2+}$. The interaction energies for $\mathrm{Zn}^{2+}, \mathrm{Cd}^{2+}$, and $\mathrm{Na}^{+}$are similar; the weakest interaction with the base is predicted for $\mathrm{Ca}^{2+}$ and $\mathrm{Mg}^{2+}$ ions.

The binding to the phosphate group appears to be less complex than for the guanine base, and the resultant complexes differ by fine changes of the metal-oxygen bond lengths. The $\mathrm{P}=\mathrm{O}$ bond of the oxygen nearest to the metal ion is increased upon the binding, thus acquiring a single-bond character, whereas the two other $\mathrm{P}=\mathrm{O}$ bonds are shortened. Only the $\mathrm{Cu}^{2+}$ ion does not cause any significant length changes of the $\mathrm{P}=\mathrm{O}$ bonds. We explain this by a balance of the electron-donation effects from the copper $\mathrm{d} / \mathrm{s}$ orbital space and an electronwithdrawal caused by the metal charge. The binding energies (last column of Table 1) indicate that $\mathrm{Cu}^{2+}$ and $\mathrm{Ni}^{2+}$ have the highest affinity for the phosphate groups, similarly as for the guanine base, although they still prefer the base. The phosphate binding of the $\mathrm{Cd}^{2+}$ and $\mathrm{Ca}^{2+}$ ions is the weakest. The relative interaction energies are in agreement with the general experimental experience, where the $\mathrm{Cu}^{2+}, \mathrm{Ni}^{2+}, \mathrm{Zn}^{2+}$, and $\mathrm{Cd}^{2+}$ transition metals prefer binding to the base. The alkaline and alkaline-earth metals bind to both the base and the phosphate with similar affinities, also in agreement with the previous experiments. ${ }^{6}$

Next, we investigate the energetic and geometry changes caused by the explicit hydration of the ions. The optimized geometries are plotted in Figure 3, and the results are summarized in Table 2. The water molecules prevent moving of the $\mathrm{Zn}^{2+}$ and $\mathrm{Mg}^{2+}$ ions from N7 to the O6 binding site, which documents one of the restrictions of the continuum model. In 

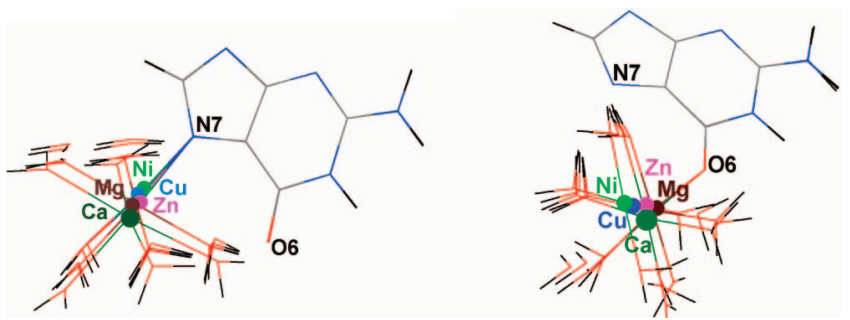

Figure 3. Optimized (B3LYP/CPCM/6-31+G**) geometries of the explicitly hydrated metal complexes with the N7 (left) and O6 (right) guanine binding sites.

comparison with the dielectric model, the explicit hydration sphere causes a minor increase of the bond lengths between the metal and the electron-donating site. For example, the $\mathrm{N} 7-\mathrm{Cu}^{2+}$ distance increases from 1.91 (Table 1) to $1.98 \AA$ (Table 2). The binding energies obtained from the explicitly hydrated models listed in Table 2 are generally lower than those predicted by the continuum and are better suit to the free energies observed in the DNA - metal binding experiments. ${ }^{52,53}$

In both models the $\mathrm{Cu}^{2+}$ ion binds most strongly at the $\mathrm{N} 7$ position, and exhibits an exceptional preference for the N7 site over O6. The $\mathrm{Cu}^{2+}$ binding to the $\mathrm{N} 3$ site provided lower interaction energies (not shown) than for the N7 or O6 complexes. Therefore, binding to this site can occur only after the other sites are occupied, which is quite improbable in real systems.

The $\mathrm{Ni}^{2+}$ ion distinctly prefers the O6 site $(E=-6 \mathrm{kcal} /$ mol), whereas the other metals (except $\mathrm{Cu}$ ) exhibit similar affinity for both $\mathrm{N} 7$ and $\mathrm{O6}$, within $\sim 2 \mathrm{kcal} / \mathrm{mol}$. The calcium is relatively weakly bound to both positions. It is the furthest from the two binding sites (Figure 3), probably because this metal has the largest ionic radius among the studied ions ${ }^{54}$ It is also interesting to note that the geometries of the $\mathrm{Zn}^{2+}$ and $\mathrm{Mg}^{2+}$ complexes, having similar ionic radii, ${ }^{54}$ are very similar for both $\mathrm{N} 7$ and $\mathrm{O} 6$ binding. However, the interaction energy for the N7 site is lower for zinc than for magnesium, in agreement with the available data. ${ }^{32-34,38,55}$

Calculated Spectra. Frequencies of the most intense transitions are listed in Table 3, and the spectra can be seen in Figure 4. The binding of the metal ions to the guanine base (solid line in Figure 4) significantly changes frequencies of many vibrational bands. For example, the $\mathrm{O} 6$ binding of $\mathrm{Mg}^{2+}, \mathrm{Ca}^{2+}$, and $\mathrm{Zn}^{2+}$ leads to a huge down-shift and an intensity loss of the $\mathrm{C} 6=\mathrm{O} 6$ stretching (calculated at $1678 \mathrm{~cm}^{-1}$ for dGMP, shifted down, e.g., to $1542 \mathrm{~cm}^{-1}$ for $\mathrm{Zn}^{2+}$ ). The frequency shifts correlate with the $\mathrm{C}=\mathrm{O}$ lengths that increase upon the metal binding (Table 1). However, a direct metal binding to this site most probably does not occur in reality because of the competition with the water molecules, as discussed below.

The N7 binding also causes notable but less extensive frequency changes. As an extreme case, the $\mathrm{Cd}^{2+}$ ion shifts the carbonyl band up by $16 \mathrm{~cm}^{-1}$. At the same time, the $\mathrm{C}=\mathrm{O}$ bond in this complex is strengthened, and its length is shortened by $0.004 \AA$ (Table 1 ). This $\mathrm{C}=\mathrm{O}$ shift is accompanied by a similar shift and splitting of the $1586 / 1569 \mathrm{~cm}^{-1}$ guanine ring modes for all the N7-binding metals $\left(\mathrm{Cu}^{2+}, \mathrm{Ni}^{2+}\right.$, and $\left.\mathrm{Cd}^{2+}\right)$. The influence on the distant sugar and phosphate moieties vibrating within $\sim 800-1100 \mathrm{~cm}^{-1}$ is quite surprising. This suggests a long-range vibrational coupling and electron-induction effects between the base and the sugar-phosphate groups. Additionally, the $\mathrm{Cu}^{2+}$ ion causes a significant loss of the absorption within $1000-1100 \mathrm{~cm}^{-1}$ (Figure 4).

As pointed out previously ${ }^{29}$ and also confirmed by the frequency shifts listed in the present study in Table 3, many of the dGMP vibrational changes caused by the metal ions can be induced purely electrostatically by point charges. For example, the $\mathrm{C}=\mathrm{O}$ stretching frequency $\left(1678 \mathrm{~cm}^{-1}\right)$ increased to 1688 $\mathrm{cm}^{-1}$ by the copper ion undergoes a similar shift to $1684 \mathrm{~cm}^{-1}$ if the $+2 \mathrm{e}$ charge is placed at the same position. Besides dispersion, polarization, charge transfer effects, etc., ${ }^{32-34,38}$ the direct electrostatic interaction thus seems to be the dominant force mediating the vibrational changes caused by the metals. Interestingly, unlike for the metals, no substantial changes are seen below $1100 \mathrm{~cm}^{-1}$ in the sugar-phosphate region (spectra not shown), which suggests that the electron-transfer and induction/polarization effects in the metal complexes become important at the longer distances in this case.

A direct binding of the bare metal ions to the phosphate group also causes a minor frequency shift of the distant carbonyl and base vibrations (Figure 4 and Table 4), possibly due to the longrange vibrational coupling and electron-induction effects mentioned above. As expected, the sugar-phosphate vibrations (below $1200 \mathrm{~cm}^{-1}$ ) are affected much more strongly. The $\mathrm{P}=\mathrm{O}$ asymmetric stretching bands at $1044 / 1029 \mathrm{~cm}^{-1}$ become more separated in all phosphate complexes (plotted by the dashed line in Figure 4). The smallest separation is seen for $\mathrm{Na}^{+}$and $\mathrm{Ca}^{2+}\left(\sim 60-90 \mathrm{~cm}^{-1}\right)$, the largest separation of $\sim 158 \mathrm{~cm}^{-1}$ is caused by the zinc. The $\mathrm{P}=\mathrm{O}$ asymmetric stretching band intensity decreases, following the ordering $\mathrm{Na}^{+}>\mathrm{Mg}^{2+}>\mathrm{Ca}^{2+}$ $>\mathrm{Zn}^{2+}>\mathrm{Cd}^{2+}>\mathrm{Ni}^{2+}>\mathrm{Cu}^{2+}$. The symmetric $\mathrm{P}=\mathrm{O}$ vibration at $887 \mathrm{~cm}^{-1}$ shifts either to higher (for $\mathrm{Na}^{+}, \mathrm{Mg}^{2+}, \mathrm{Ca}^{2+}$, and $\left.\mathrm{Cu}^{2+}\right)$ or to lower $\left(\mathrm{Zn}^{2+}, \mathrm{Cd}^{2+}\right.$, and $\left.\mathrm{Ni}^{2+}\right)$ values. Because of the strong coupling of the vibrations in this region it is difficult to rationalize all the observed spectral changes by a simple cause. However, it is clear that differences in the metal ion effect on the spectra originate not only from the electrostatic interactions but also from the ion polarization and electron-transfer associated with the binding.

Explicit Hydration. The frequency shifts predicted with the dielectric solvent model can be compared to those caused by the pentahydrated ions bound to the N7/O6 sites in Table 5 and Figure 5. The spectral changes are more moderate compared to the implicit hydration, and the frequency shifts better correspond to the experimental values listed at the bottom part of Table 5. We can thus see that not only are the energies (Table 2) more realistic, but the frequency changes are more moderate in comparison with the bare metal ions (cf., Tables 3 and 5). Most importantly, some of the water-metal competition effects can be modeled this way. These results confirm previous findings that the proper solvent model is crucial for description of the polar interactions between the ions and nucleic acid components. ${ }^{32-34,38,55,56}$ Particularly for polar systems, the implicit polarizable continuum models provide only a limited accounting for the directional hydrogen and metal-complex bonds $;^{34,57}$ explicitly hydrated ions are thus needed for a more accurate modeling.

Apart from making hydrogen bridges, the explicit water molecules cause a significant geometrical hindrance for the binding, finally resulting in notably different spectra if compared to bare metal ions or implicit hydration. This is documented in Figure 6 for the zinc ion in a complex with dGMP and one water molecule, placed in the dielectric environment. In comparison with the free dGMP (upper spectrum in Figure 6), a direct binding of the metal to O6 (structures 0 and 2) causes an unrealistically low carbonyl vibration shifts (cf. also Table 3). The bands at 1686 (structure 0) and $1673 \mathrm{~cm}^{-1}$ (structure 2) belong to the guanine ring $v(\mathrm{C}=\mathrm{C})$ mode vibrating at $1556 \mathrm{~cm}^{-1}$ in free dGMP. How sensitive the normal mode distribution is 
TABLE 2: Calculated (B3LYP/CPCM/6-31+G**) Distances $(d$, in $\AA$ ) and Relative Binding Energies $(E, \mathrm{kcal} / \mathrm{mol})$ for the Explicitly Hydrated Metal Ions Interacting with the Guanine Base

\begin{tabular}{|c|c|c|c|c|c|c|c|c|}
\hline \multirow{2}{*}{$\begin{array}{c}\text { metal } \\
\text { ion }\end{array}$} & \multicolumn{4}{|c|}{ N7 binding } & \multicolumn{4}{|c|}{ O6 binding } \\
\hline & $d(\mathrm{~N} 7-\mathrm{M})$ & $d(\mathrm{O} 6-\mathrm{M})$ & $d(\mathrm{C}=\mathrm{O} 6)$ & $E$ & $d(\mathrm{~N} 7-\mathrm{M})$ & $d(\mathrm{O} 6-\mathrm{M})$ & $d(\mathrm{C}=\mathrm{O} 6)$ & $E$ \\
\hline none & & & 1.240 & & & & 1.240 & \\
\hline $\mathrm{Ca}^{2+}$ & 2.55 & 3.70 & 1.258 & -3 & 3.84 & 2.37 & 1.256 & -5 \\
\hline $\mathrm{Cd}^{2+}$ & 2.31 & 3.56 & 1.257 & -6 & 3.68 & 2.28 & 1.259 & -5 \\
\hline $\mathrm{Zn}^{2+}$ & 2.10 & 3.51 & 1.258 & -9 & 3.55 & 2.09 & 1.261 & -7 \\
\hline $\mathrm{Ni}^{2+}$ & 1.88 & 3.52 & 1.255 & 0.2 & 3.41 & 2.58 & 1.247 & -6 \\
\hline
\end{tabular}

TABLE 3: Calculated (B3LYP/CPCM/6-31+G**) Harmonic Vibrational Frequencies of dGMP Providing the Strongest IR Signal and Frequency Changes in the Complexes with Metal Ions Bound to the Base

\begin{tabular}{|c|c|c|c|c|c|c|c|c|c|c|c|c|c|}
\hline \multicolumn{13}{|c|}{ wavenumbers, $\mathrm{cm}^{-1}$} & \multirow[b]{2}{*}{ assignment } \\
\hline dGMP & $\mathrm{Na}^{+}$ & $\mathrm{Mg}^{2+}$ & $\mathrm{Ca}^{2+}$ & $\mathrm{Zn}^{2+}$ & $\mathrm{Zn}^{2+a}$ & $\mathrm{Zn}^{2+b}$ & $\mathrm{Cd}^{2+}$ & $\mathrm{Ni}^{2+}$ & $\mathrm{Cu}^{2+}$ & $0.5 \mathrm{e}^{+}$ & $1 \mathrm{e}^{+}$ & $2 \mathrm{e}^{+}$ & \\
\hline \multicolumn{14}{|c|}{ Base Modes } \\
\hline 1678 & 1663 & 1564 & 1568 & 1542 & 1659 & 1545 & 1694 & 1690 & 1688 & 1681 & 1682 & 1684 & $v(\mathrm{C}=\mathrm{O}) \mathrm{G}$ \\
\hline 1586 & 1547 & 1634 & 1616 & 1648 & 1608 & 1607 & 1602 & 1616 & 1613 & 1588 & 1597 & & ring $\mathrm{G}$ \\
\hline 1569 & 1582 & 1588 & 1583 & 1583 & 1588 & 1590 & 1576 & 1574 & 1576 & 1571 & 1571 & 1577 & ring $\mathrm{G}+v\left(\mathrm{C}-\mathrm{ND}_{2}\right) \mathrm{G}$ \\
\hline 1556 & & 1669 & 1673 & 1683 & 1571 & 1673 & & & & & & 1563 & $v(\mathrm{C}=\mathrm{C}) \mathrm{G}$ \\
\hline \multicolumn{14}{|c|}{ Sugar-Phosphate Modes } \\
\hline 10441029 & 1017943 & 10631047 & 10621045 & 10811058 & 10601045 & 10491035 & 10731058 & 10521002 & 1144 & 10461027 & 10441029 & $\begin{array}{l}10451028 \\
966\end{array}$ & $\begin{array}{l}v(\mathrm{P}=\mathrm{O}) \text { asym } \\
\delta(\mathrm{C}-\mathrm{H}, \mathrm{N}-\mathrm{H})\end{array}$ \\
\hline 948 & & 947 & 946 & 958 & 962 & 948 & 954 & & & 945 & 943 & 929 & $\delta$ sugar, $v(\mathrm{C}-\mathrm{C})$ sugar \\
\hline \multirow[t]{2}{*}{887} & 820 & 892 & 892 & 925 & 889 & 893 & 925 & 890 & 940 & 894 & 894 & 894 & $\begin{array}{c}v(\mathrm{P}=\mathrm{O}) \operatorname{sym} / v(\mathrm{P}=\mathrm{O}) \\
\text { sym }+\delta \text { sugar }\end{array}$ \\
\hline & & 865 & 874 & 881 & & & 889 & & & 877 & 878 & 874 & $\delta$ sugar \\
\hline
\end{tabular}

${ }^{a}$ Explicit water molecule between $\mathrm{Zn}$ and O6. ${ }^{b}$ Explicit water molecule between $\mathrm{Zn}$ and N7.

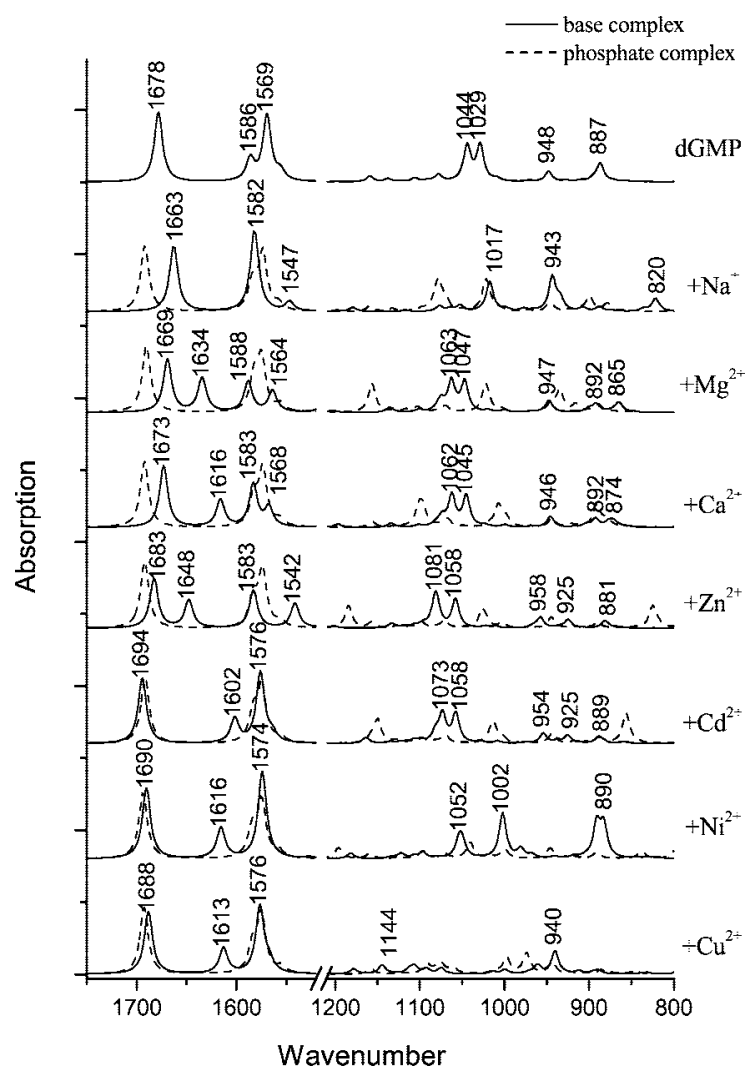

Figure 4. Calculated (B3LYP/CPCM/6-31+G**) IR spectra of dGMP and its complexes with metal ions bound to the guanine base (solid line) and the phosphate group (dashed line). Wavenumbers indicated correspond to the base binding. Wavenumbers for the phosphate binding are listed in Table 4.

to the base environment can be documented on the binding of the water molecule to N7 (Cf. structures 0 and 2 in Figure 6), causing a large redistribution of the IR intensities of the ring vibrational modes. When the water is placed near O6 (structure
1), the binding of the metal to N7 stabilizes, and the carbonyl frequency shifts down only slightly, in favor to the experimental observations. As for the peptide group hydration, ${ }^{57,58}$ we thus find that the continuum solvent models have to be used consciously for modeling of the geometry and vibrational properties of the polar nucleic acid-metal complexes.

Contrary to the general belief, the direct binding of the metal to O6 causes a smaller down-shift of the carbonyl frequency than the hydrogen bond formation with water molecules from the metal ion hydration shell. This is illustrated especially well for $\mathrm{Mg}^{2+}, \mathrm{Ca}^{2+}$, and $\mathrm{Ni}^{2+}$ in Figure 5, where the water bound to $\mathrm{O} 6$ in the $\mathrm{N} 7$ complexes causes a larger downshift (up to $1662 \mathrm{~cm}^{-1}$ for $\mathrm{Ni}^{2+}$ ) than the directly bound metal in the $\mathrm{O} 6$ complexes. Supposedly, the oxygen-metal bond is weaker than the hydrogen bonds between the carbonyl oxygen and closest water molecules. Consequently, the metal ion hydration shell might affect the vibrational spectra much more than the ion itself. On the other hand, the hydrogen bonding might mask the vibrational detection of electrostatic, dispersion, polarization, and other specific interactions.

In contrast to the aforementioned complications associated with the carbonyl stretching mode, the guanine base vibrations (at $1577 \mathrm{~cm}^{-1}$, with a shoulder at $1589 \mathrm{~cm}^{-1}$, Figure 5) appear as more reliable marker bands. The split in two components in all complexes and the high-wavenumber shift correlates with the metal ion affinity and binding energy. The shift is smaller for $\mathrm{Ca}^{2+}$ and $\mathrm{Mg}^{2+}$ and is larger for $\mathrm{Cu}^{2+}, \mathrm{Ni}^{2+}, \mathrm{Cd}^{2+}$, and $\mathrm{Zn}^{2+}$. However, in the $\mathrm{Ca}^{2+}$ and $\mathrm{Mg}^{2+}$ complexes the shift is very similar for both $\mathrm{N} 7$ and $\mathrm{O} 6$ binding (within $1 \mathrm{~cm}^{-1}$ ), suggesting a low specificity of the ring vibration to the binding mode for these two metals. On the contrary, the transition metal ions shift the ring absorption band much more in the N7 complexes (up to $9 \mathrm{~cm}^{-1}$ ) than in the $\mathrm{O} 6$ ones, possibly due to participation of the d-orbitals in the N7 binding but not in the O6 complexes.

Experimental Spectra. How the metals actually bind can be verified from the experimental spectra (Figure 7) recorded 
TABLE 4: Calculated (B3LYP/CPCM/6-31+G**) Harmonic Vibrational Frequencies of dGMP Providing the Strongest IR Signal and Frequency Changes in the Complexes with Metal Ions Bound to the Phosphate

\begin{tabular}{|c|c|c|c|c|c|c|c|c|}
\hline \multicolumn{8}{|c|}{ wavenumbers, $\mathrm{cm}^{-1}$} & \multirow[b]{2}{*}{ assignment } \\
\hline dGMP & $\mathrm{Na}^{+}$ & $\mathrm{Mg}^{2+}$ & $\mathrm{Ca}^{2+}$ & $\mathrm{Zn}^{2+}$ & $\mathrm{Cd}^{2+}$ & $\mathrm{Ni}^{2+}$ & $\mathrm{Cu}^{2+}$ & \\
\hline \multicolumn{9}{|c|}{ Base Modes } \\
\hline 1586 & 1583 & 1583 & 1583 & 1584 & 1583 & 1583 & 1584 & $\operatorname{ring} \mathrm{G}$ \\
\hline 1569 & 1574 & 1575 & 1574 & 1574 & 1575 & 1575 & 1575 & ring $\mathrm{G}+v\left(\mathrm{C}-\mathrm{ND}_{2}\right) \mathrm{G}$ \\
\hline \multicolumn{9}{|c|}{ Sugar-Phosphate Modes } \\
\hline 948 & 946 & & 944 & 945 & 944 & 944 & 998 & $\delta$ sugar, $v(\mathrm{C}-\mathrm{C})$ sugar \\
\hline \multirow[t]{2}{*}{887} & 899 & 935 & 891 & 825 & 856 & 836 & 974 & $v(\mathrm{P}=\mathrm{O}) \operatorname{sym} / v(\mathrm{P}=\mathrm{O})$ sym $+\delta$ sugar \\
\hline & 878 & & & & & & 944 & $\delta$ sugar \\
\hline
\end{tabular}

TABLE 5: Calculated (B3LYP/CPCM/6-31+G**) Vibrational Frequencies of the Pentahydrated Metal-Guanine Complexes As Compared to the Experimental Values (20:1 ratio) for dGMP-Metal Complexes

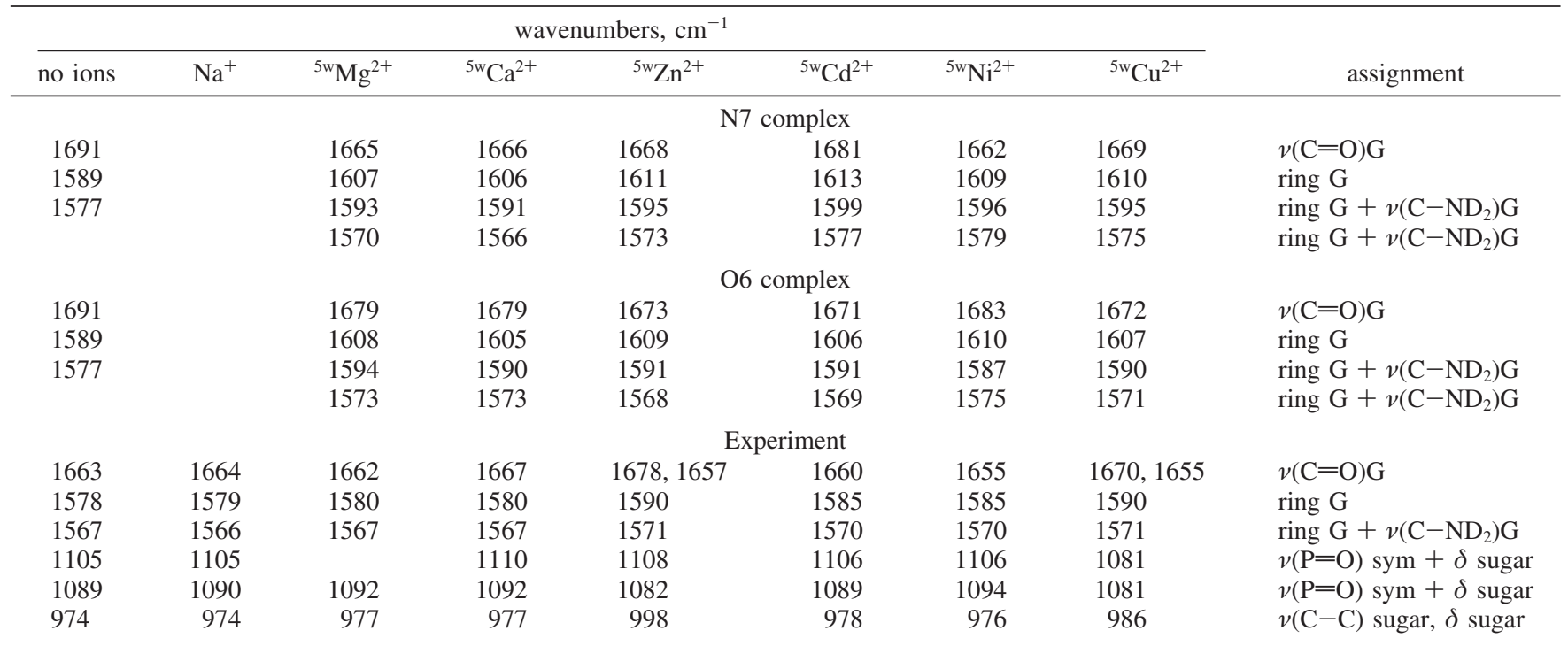

for 1:1 and 20:1 metal/dGMP molar ratios. Note, that because the dGMP was used in the form of the disodium salt, the "free dGMP" spectrum actually represents a 2:1 Na+/dGMP ratio. In spite of the inhomogeneous broadening of the experimental absorption bands, the main observable transitions can be identified and correspond well to the theoretical predictions (Cf. Figures 4 and 5). Particularly, the frequencies are close to those predicted for the hydrated complex models, and the assignments listed in Table 5 are consistent with earlier works. ${ }^{11,24,25}$

A closer look reveals significant differences in the behavior of the metals. The $\mathrm{Na}^{+}$ions virtually do not modify the IR spectrum even at the 20-fold excess, which can be explained by the energetically unfavorable complex formation and a weakness of the electrostatic interactions screened for the dissolved metal by the solvent. ${ }^{6-8}$ The computed changes for the sodium complexes (Figure 4 and Tables 3 and 4) are not present in the experiment; thus, this ion most probably does not bind to dGMP site-specifically. We have also carried out an experiment with potassium ions, mixed with dGMP at the 1:1 and 20:1 ratios; however, the spectral effects were negligible as for $\mathrm{Na}^{+}$. Therefore, we only analyze the results obtained with sodium.

The $\mathrm{Mg}^{2+}$ ions produce larger changes, but mostly in the sugar-phosphate vibrating region. This is consistent with the calculated preferential binding or at least with a weak complexation of this metal with the phosphate group. The computed spectral modifications for the base-bound $\mathrm{Mg}^{2+}$ are not observed, which suggests the absence of a site-specific base interaction.
The $\mathrm{Ca}^{2+}$ ion behaves essentially as the magnesium, inducing analogous changes in the sugar-phosphate region, but the shifts of the base vibrations seem to be more dependent on the concentration. For the 20:1 ratio the carbonyl band moves from 1663 to $1667 \mathrm{~cm}^{-1}$, indicating a moderate interaction with this group. The observed spectral changes suggest that the calcium binds mainly to the phosphate groups at low concentrations and might start to interact with the guanine base at higher concentrations. The calculated relative binding energies for the base and phosphate binding (Table 1) also support this conclusion. Most probably, $\mathrm{Ca}^{2+}$ prefers the $\mathrm{O} 6$ base binding site, which would be consistent with the predicted and observed spectral changes and binding energies computed for the hydrated complexes (Table 2).

Unlike the alkali and alkali-earth metals, the transition metal ions $\left(\mathrm{Zn}^{2+}, \mathrm{Cd}^{2+}, \mathrm{Ni}^{2+}\right.$, and $\left.\mathrm{Cu}^{2+}\right)$ induce relatively large spectral changes already at the 1:1 ratio (Figure 7), which is indicative of a strong site-specific binding. Furthermore, the $\mathrm{Zn}^{2+}, \mathrm{Cd}^{2+}$, and $\mathrm{Ni}^{2+}$ ions do not substantially change the spectra with the concentration increase. In contrast, increasing of the $\mathrm{Cu}^{2+}$ concentration causes further spectral changes, especially in the sugar-phosphate region $\left(\sim 1020-1150 \mathrm{~cm}^{-1}\right)$, where the signal almost vanishes for the 20:1 ratio. However, a finer dependence on the concentration is also observable for the other ions.

The $\mathrm{Zn}^{2+}$-induced shift of the carbonyl band from 1663 to $1677 \mathrm{~cm}^{-1}$ at $1: 1$ ratio develops into nearly separated bands at 1678 and $1657 \mathrm{~cm}^{-1}$ for the 20:1 ratio. The ring modes shift from $1578 / 1567$ to $1590 / 1571 \mathrm{~cm}^{-1}$ at the high metal concentra- 


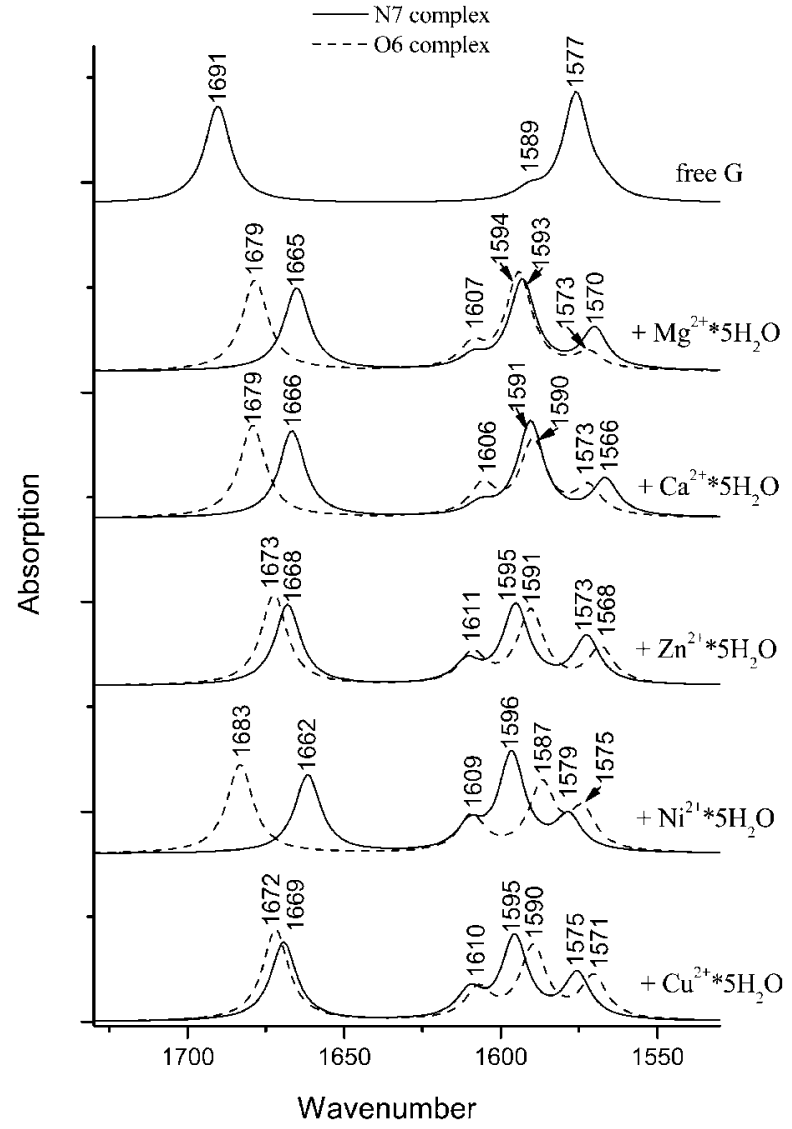

Figure 5. Calculated (B3LYP/CPCM/6-31+G**) IR spectra of guanine base and its complexes with pentahydrated metal ions bound to N7 site (solid line) and O6 site (dashed line).

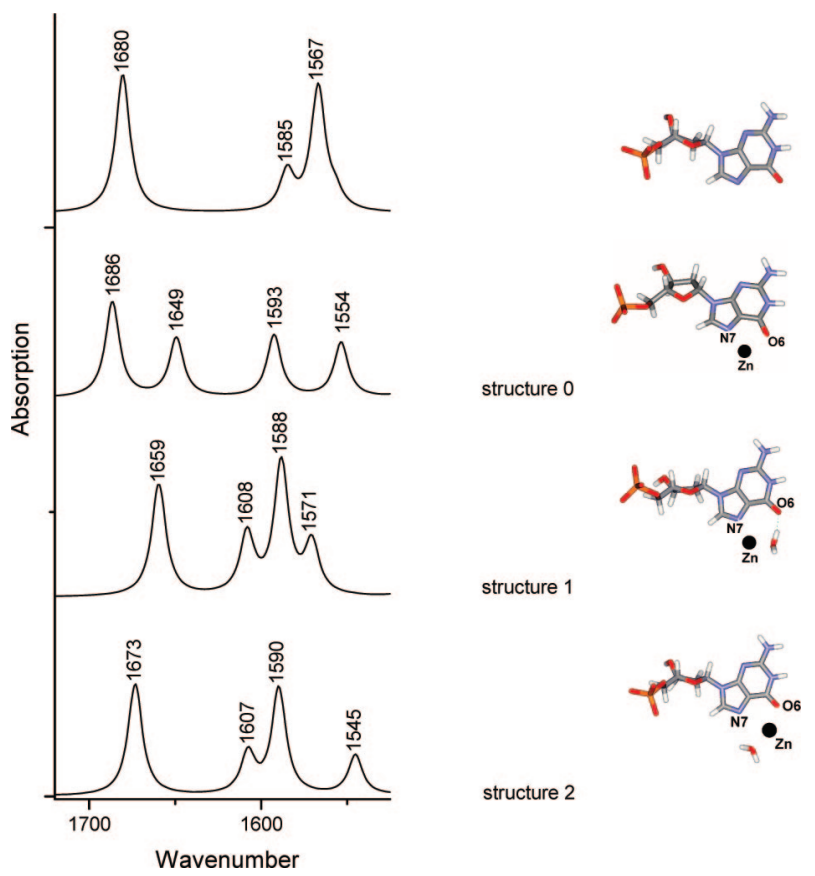

Figure 6. Calculated spectra of (from top to bottom): dGMP, bare zinc-dGMP complex and two zinc/water-dGMP complexes with different water positioning.

tion, and the intensity is redistributed between the high- and low-wavenumber components. Spectral changes in the sugarphosphate region are less pronounced. The spectral modifications thus suggest a strong $\mathrm{Zn}^{2+}$ binding to the guanine base. A weaker interaction with the phosphate group starts at the low

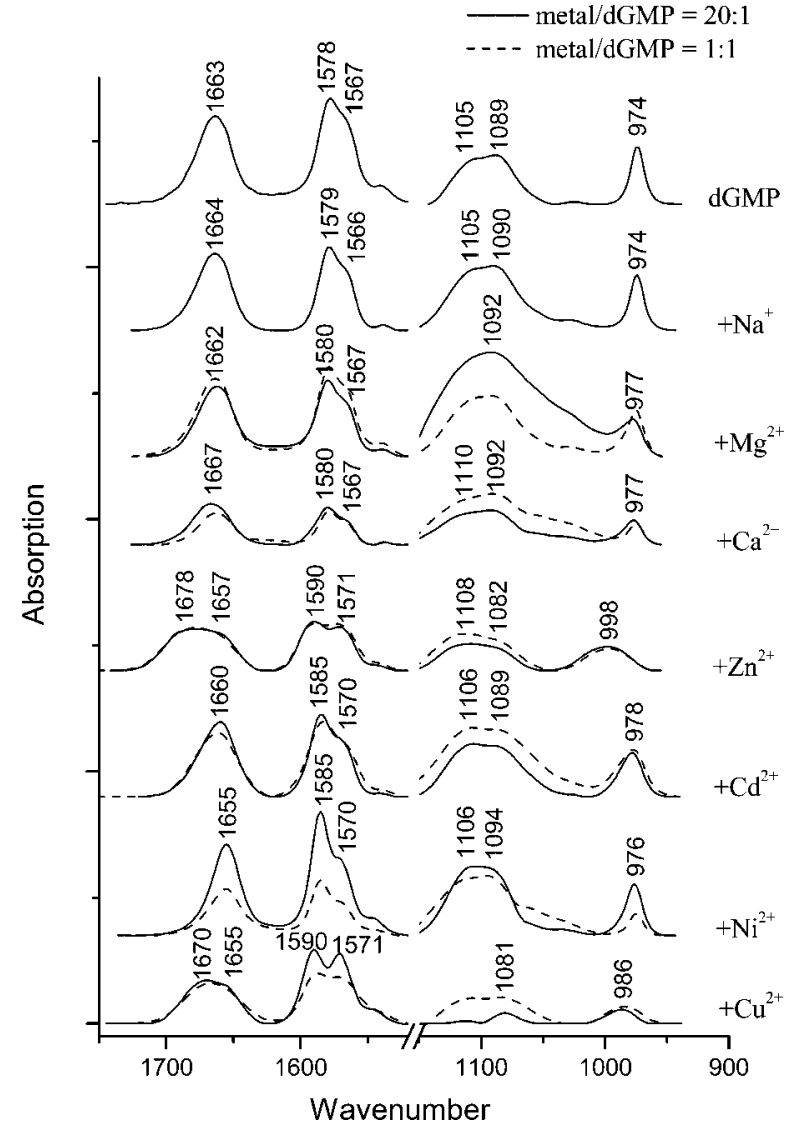

Figure 7. Experimental IR spectra of $\mathrm{D}_{2} \mathrm{O}$ solutions of dGMP and its complexes with metal ions at 1:1 and 20:1 metal/dGMP ratios. Note that the spectrum of dGMP (dGMP disodium salt) corresponds to a 2:1 $\mathrm{Na}^{+} / \mathrm{dGMP}$ ratio; for the second spectrum from the top $\left(\mathrm{Na}^{+}\right)$the molar ratio is 20:1. The wavenumbers indicated are for 20:1 complexes.

metal concentration and is probably not site-specific, similarly as for the alkaline metals. This is consistent with the predicted binding energies (Tables 1 and 2) favoring the base and, most likely, the $\mathrm{N} 7$ binding site.

The $\mathrm{Cd}^{2+}$ and $\mathrm{Ni}^{2+}$ ions produce rather minor band shape changes; however, they shift the guanine ring mode from 1578 to $1585 \mathrm{~cm}^{-1}$ for the $20: 1$ ratio. Unlike the other metals, $\mathrm{Cd}^{2+}$ and $\mathrm{Ni}^{2+}$ ions shift the carbonyl band down, from 1663 to 1660 $\mathrm{cm}^{-1}$ for cadmium and to $1655 \mathrm{~cm}^{-1}$ for nickel for the $20: 1$ ratio. Examination of the equilibrium geometry (Figure 2 and Table 2) reveals that these ions are situated further away from O6, thus possibly influencing the carbonyl vibration differently than the other ions. In the phosphate region the whole symmetric band is shifted by $\mathrm{Ni}^{2+}$ ions to the higher wavenumbers, somewhat more than for the other ions. This can be explained by the calculated strong effect of the $\mathrm{Ni}^{2+}$ ions on the phosphate (Figure 4 and Table 4), for example, the large splitting of the asymmetric bands at 1194 and $1041 \mathrm{~cm}^{-1}$ and intensity decrease.

Undoubtedly, the $\mathrm{Cu}^{2+}$ ions induce the largest changes in the experimental spectra (Figure 7). The changes progress with the metal concentration increase. The carbonyl band shifts from 1663 to $1667 \mathrm{~cm}^{-1}$ at $1: 1$ ratio and further splits into two overlapping bands at 1670 and $1655 \mathrm{~cm}^{-1}$ at the $20: 1$ ratio. The guanine ring modes at $1578 / 1567 \mathrm{~cm}^{-1}$ also shifted to the higher wavenumbers at $1590 / 1571 \mathrm{~cm}^{-1}$. These two bands become separate at the 20:1 ratio and significantly gain in intensity. Similar spectral changes were observed by Fritzsche and Zimmer for the $\mathrm{Cu}^{2+}$ binding to guanine and were attributed 


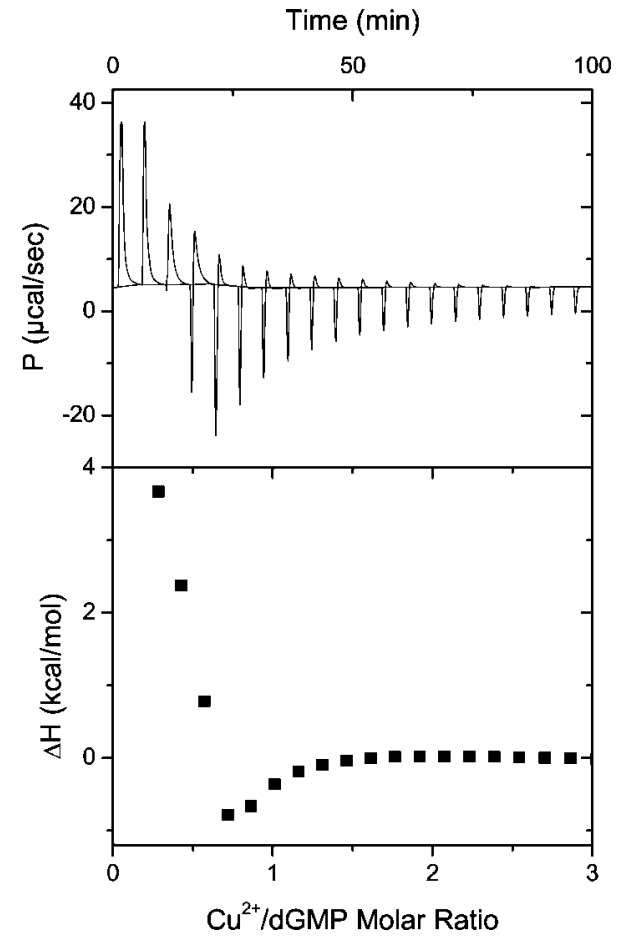

Figure 8. ITC titration of the $\mathrm{Cu}^{2+}-\mathrm{dGMP}$ binding at $25^{\circ} \mathrm{C}$ : the heat power (up) and the total heat of the reaction (bottom, obtained by peak integration of the titration trace and corrected for the heat of the $\mathrm{CuCl}_{2}$ dilution) as a function of the $\mathrm{Cu}^{2+} / \mathrm{dGMP}$ molar ratio.

to the interaction with the N7 site. ${ }^{11}$ The present results are consistent with such an assignment based both on the computed spectral changes and the relative binding energies. Furthermore, we suppose that at high concentrations $\mathrm{Cu}^{2+}$ starts to also bind site-specifically to the phosphate group, as the phosphatevibration region in the experimental spectrum is significantly modified at high copper concentration (Figure 7). This is consistent with the computations predicting the intensity loss of the phosphate vibrational modes (Figure 4).

The ITC experiment monitoring the copper-dGMP binding indicates two processes competing during the titration as well (Figure 8). The first process is endothermic and occurs at low metal ion concentrations, finishing at about 1:1 metal/dGMP molar ratio. At about 0.7:1 ratio the monotonic decrease of the titration curve is overlaid by an exothermic process observable approximately to the $2: 1$ concentration ratio. The combination of the ab initio, IR spectroscopic, and ITC data thus suggests that the endothermic event is related to the $\mathrm{Cu}^{2+}$ binding to the N7 site of guanine, whereas the exothermic process might be related to the site-specific metal-phosphate complexation, occurring after the more favorable N7 positions are occupied.

Computational Aspects. Although the computations appear indispensable for the correct interpretation of the metal-dGMP binding and the inclusion of the solvent significantly improved the results, their accuracy remains limited. The continuum solvent model lead to an overestimation of the O6 site binding, which resulted in an unrealistic shift of the carbonyl band, which was not observed experimentally. This could be only partially fixed by the explicit hydration shell, which still causes a small but acceptable downshift of this band due to the formation of the hydrogen bonds. Clearly, a more accurate dynamical hydration model is desirable that would account, namely, for the inhomogeneous broadening of the phosphate and carbonyl stretching bands; this is, however, beyond the scope of the present study.
The main computed trends in the metal ion effect on the spectra could be well correlated with the experiment. The accompanying high-wavenumber shift of the guanine ring vibrations around $1580 \mathrm{~cm}^{-1}$ was proposed by Fritzsche and Zimmer ${ }^{11}$ as the most important indication of the metal binding to N7 of guanine and could be reliably reproduced by our calculations. The predicted similar spectral behavior of the $\mathrm{Cu}^{2+}$ and $\mathrm{Zn}^{2+}$ ions was also observed experimentally. The intensity loss of the phosphate vibrations upon the $\mathrm{Cu}^{2+}$ binding was reproduced by the calculation; however, the present model does not allow for a direct comparison of the theoretical and experimental spectral shapes in this region.

Unlike in our previous vacuum modeling of IR and VCD spectra of nucleic acid fragments, ${ }^{28,30}$ in this study we use the B3LYP functional instead of BPW91. Control computations (not shown) indicate that the BPW91 level in connection with the solvent model produces too low frequencies of the polar groups ( $\mathrm{P}=\mathrm{O}$ and $\mathrm{C}=\mathrm{O}$ stretching). Generally, the B3LYP method produces more balanced results in a wider spectral region, especially if coupled with the COSMO solvent correction.

\section{Conclusions}

We used the density functional theory computations for prediction of the preferential binding sites, geometries, and vibrational spectra of the complexes of common metals with the guanosine $5^{\prime}$-monophosphate as a principal nucleic acid component. Unlike in previous models, the solvent was included via continuum and a combined explicit/continuum approximations, which resulted in more reasonable calculations of binding energies, geometries, and spectral changes. The predicted effects could be utilized for interpretation of the experimental IR data. Observed binding patterns could be well-related to previous experiments and specific binding properties of various metals. The data showed that most metals interact nonspecifically with the sugar-phosphate residue due to the electrostatic interaction. Only the copper ions at high concentrations exhibit effects corresponding to a specific binding to the phosphate residue, which could be confirmed by the microcalorimetry titration. The base $\mathrm{N} 7$ binding of the $\mathrm{Zn}^{2+}, \mathrm{Cd}^{2+}, \mathrm{Ni}^{2+}$, and $\mathrm{Cu}^{2+}$ ions is associated with specific changes in the spectra, such as the highfrequency shift of the guanine modes at $\sim 1580 \mathrm{~cm}^{-1}$, and could be interpreted with the aid of the calculations. The interpretation of the spectra based on the ab initio modeling can thus significantly contribute to better understanding of the DNA and RNA interactions with the metal ions studied by the vibrational spectroscopy.

Acknowledgment. The work was supported by the Grant Agency of the Czech Republic (grants 203/06/0420 and 202/ 07/0732) and Grant Agency of the Academy of Sciences (A400550702 and A400550701). We thank Tomáš Kraus for the help with the calorimetric titrations and Vladimír Baumruk for the help with the Raman experiment.

\section{References and Notes}

(1) Bloomfield, V. A. Biopolymers 1997, 44, 269.

(2) Metal ions in Genetic Information Transfer; Eichhorn, G. L., Marzilli, L. G., Eds.; Elsevier/North-Holland: New York, 1981; Vol. 3.

(3) Izatt, R. M.; Christensen, J. J.; Rytting, J. H. Chem. Rev. 1966, 66, 439.

(4) Lerman, L. S. Cold Spring Harb. Symp. Quant. Biol. 1973, 38, 59.

(5) Metal Ions in Biological Systems. Interactions of Metal Ions with Nucleotides, Nucleic Acids and Their Constituents; Sigel A., Sigel, H., Eds.; Marcel Dekker: New York, 1996; Vol. 32.

$31,165$.
(6) Sissoeff, I.; Grisvard, J.; Guille, E. Prog. Biophys. Mol. Biol. 1976, 
(7) Saenger, W. Principles of Nucleic Acid Structure; Springer-Verlag: New York, 1984

(8) Blagoi, Y. P.; Galkin, V. L.; Gladchenko, G. O.; Kornilova, S. V.; Sorokin, V. A.; Shkorbatov, A. G. Metal Complexes of Nucleic Acids in Solutions; Naukova Dumka: Kiev, Ukraine, 1991.

(9) Marzilli, L. G.; Kistenmacher, T. J.; Eichhorn, G. L. Structural principles of metal ion-nucleotide and metal ion-nucleic acid interactions. In Nucleic Acid-Metal Ion Interactions; Spiro, T. G., Ed.; John Wiley \& Sons: New York, 1980; pp 180.

(10) Šponer, J.; Leszczynski, J.; Hobza, P. Biopolymers 2001, 61, 3.

(11) Fritzsche, H.; Zimmer, C. Eur. J. Biochem. 1968, 5, 42.

(12) Zimmer, C.; Luck, G.; Fritzsche, H.; Triebel, H. Biopolymers 1971, $10,441$.

(13) Tu, A. T.; Friederich, C. G. Biochemistry 1968, 7, 4367.

(14) Loprete, D. M.; Hartman, K. A. Biochemistry 1993, 32, 4077.

(15) Tajmir-Riahi, H. A.; Theophanides, T. Inorg. Chim. Acta Bioinorg. Chem. 1983, 80, 223.

(16) Theophanides T.; Tajmir-Riahi, H. A. Spectroscopic properties of metal-nucleotide and metal-nucleic acid interactions. In Spectroscopy of Biological Molecules; Sandorfy, C., Theophanides, T., Eds.; Reidel: Dordrecht, Netherlands, 1984; p 137.

(17) Tajmir-Riahi, H. A.; Naoui, M.; Ahmad, R. Biopolymers 1993, 33, 1819.

(18) Kornilova, S.; Hackl, E.; Kapinos, L.; Andrushchenko, V.; Blagoi, Y. Acta Biochim. Pol. 1998, 45, 107.

(19) Kornilova, S. V.; Kapinos, L. E.; Tomkova, A.; Mishkovskii, P.; Blagoi Iu, P.; Bol'bukh, T. V. Biofizika 1994, 39, 423.

(20) Andrushchenko, V.; Leonenko, Z.; Cramb, D.; van de Sande, H.; Wieser, H. Biopolymers 2001, 61, 243.

(21) Andrushchenko, V.; Tsankov, D.; Wieser, H. J. Mol. Struct. 2003 661,541

(22) Andrushchenko, V.; van de Sande, J. H.; Wieser, H. Biopolymers 2003, 72,374

(23) Andrushchenko, V. V. VCD and IR spectroscopic study of metal ion induced structural changes of synthetic and natural nucleic acids at different temperatures Thesis/Dissertation, PhD, University of Calgary, 2000.

(24) Tsuboi, M. Infrared and Raman spectroscopy. In Basic Principles in Nucleic Acid Chemistry; Ts'o, P. O. P., Ed.; Academic Press: New York, 1974; Vol. 1; pp 399.

(25) Tsuboi, M.; Takahashi, S.; Harada, I. Infrared and Raman spectra of nucleic acids - vibrations in the base-residues. In Physico-Chemical Properties of Nucleic Acids; Academic Press: London, 1973; Vol. 2, pp 91.

(26) Taillandier, E.; Liquier, J. Methods Enzymol. 1992, 211, 307.

(27) Taillandier, E.; Liquier, J.; Taboury, J. A. Infrared spectral studies of DNA conformations. In Advances in Infrared and Raman Spectroscopy; Clark, R. J. H., Hester, R. E., Eds.; Wiley-Heyden: New York, 1985; Vol 12 , pp 65.

(28) Andrushchenko, V.; Wieser, H.; Bouř, P. J. Phys. Chem. B 2004, 108, 3899 .

(29) Andrushchenko, V.; Wieser, H.; Bouř, P. J. Phys. Chem. A 2007, $111,9714$.

(30) Bouř, P.; Andrushchenko, V.; Kabeláè, M.; Maharaj, V.; Wieser, H. J. Phys. Chem. B 2005, 109, 20579.

(31) de la Fuente, M.; Navarro, R. J. Mol. Struct. 2004, 687, 7.

(32) Rulíšek, L.; Šponer, J. J. Phys. Chem. B 2003, 107, 1913.

(33) Šponer, J.; Sabat, M.; Gorb, L.; Leszczynski, J.; Lippert, B.; Hobza, P. J. Phys. Chem. B 2000, 104, 7535.
(34) Šponer, J. E.; Sychrovský, V.; Hobza, P.; Šponer, J. Phys. Chem. Chem. Phys. 2004, 6, 2772.

(35) Burda, J. V.; Šponer, J.; Hobza, P. J. Phys. Chem. 1996, 100, 7250.

(36) Munoz, J.; Šponer, J.; Hobza, P.; Orozco, M.; Luque, F. J. J. Phys. Chem. B 2001, 105, 6051.

(37) Burda, J. V.; Šponer, J.; Leszczynski, J.; Hobza, P. J. Phys. Chem. $B$ 1997, 101, 9670.

(38) Šponer, J.; Burda, J. V.; Sabat, M.; Leszczynski, J.; Hobza, P. J. Phys. Chem. A 1998, 102, 5951.

(39) Šponer, J.; Leszczynski, J.; Hobza, P. J. Mol. Struct.Theochem 2001, $573,43$.

(40) Pavelka, M.; Shukla, M. K.; Leszczynski, J.; Burda, J. V. J. Phys. Chem. A 2008, 112, 256.

(41) Klamt, A.; Jonas, V.; Burger, T.; Lohrentz, J. C. W. J. Phys. Chem. A 1998, 102, 5074.

(42) Frisch, M. J. Trucks, G. W.; Schlegel, H. B.; Scuseria, G. E.; Robb, M. A.; Cheeseman, J. R.; Montgomery, J., J. A.; Vreven, T.; Kudin, K. N.; Burant, J. C.; Millam, J. M.; Iyengar, S. S.; Tomasi, J.; Barone, V.; Mennucci, B.; Cossi, M.; Scalmani, G.; Rega, N.; Petersson, G. A.; Nakatsuji, H.; Hada, M.; Ehara, M.; Toyota, K.; Fukuda, R.; Hasegawa, J.; Ishida, M.; Nakajima, T.; Honda, Y.; Kitao, O.; Nakai, H.; Klene, M.; Li, X.; Knox, J. E.; Hratchian, H. P.; Cross, J. B.; Bakken, V.; Adamo, C.; Jaramillo, J.; Gomperts, R.; Stratmann, R. E.; Yazyev, O.; Austin, A. J.; Cammi, R.; Pomelli, C.; Ochterski, J. W.; Ayala, P. Y.; Morokuma, K.; Voth, G. A.; Salvador, P.; Dannenberg, J. J.; Zakrzewski, V. G.; Dapprich, S.; Daniels, A. D.; Strain, M. C.; Farkas, O.; Malick, D. K.; Rabuck, A. D.; Raghavachari, K.; Foresman, J. B.; Ortiz, J. V.; Cui, Q.; Baboul, A. G.; Clifford, S.; Cioslowski, J.; Stefanov, B. B.; Liu, G.; Liashenko, A.; Piskorz, P.; Komaromi, I.; Martin, R. L.; Fox, D. J.; Keith, T.; Al-Laham, M. A.; Peng, C. Y.; Nanayakkara, A.; Challacombe, M.; Gill, P. M. W.; Johnson, B.; Chen, W.; Wong, M. W.; Gonzalez, C.; Pople, J. A. Gaussian 03, Revision C.02; Gaussian, Inc.: Wallingford CT, 2004.

(43) Sletten, E. J. Chem. Soc., Chem. Commun. 1971, 558.

(44) Aoki, K. Acta Crystallogr. B 1976, 32, 1454.

(45) Max, J. J.; Gessinger, V.; van Driessche, C.; Larouche, P.; Chapados, C. J. Chem. Phys. 2007, 126.

(46) Kapitán, J.; Baumruk, V.; Gut, V.; Hlavaček, J.; Dlouhá, H.; Urbanová, M.; Wunsch, E.; Maloň, P. Collect. Czech. Chem. Commun. 2005, $70,403$.

(47) Insight II; Accelrys, Inc.: San Diego, CA, 1995.

(48) Young, D. W.; Tollin, P.; Wilson, H. R. Acta Crystallogr., Sect. B: Struct. Sci 1974, B 30, 2012.

(49) Becke, A. D. J. Chem. Phys. 1993, 98, 1372.

(50) Hay, P. J.; Wadt, W. R. J. Chem. Phys. 1985, 82, 299.

(51) Ahlrichs, R.; Bar, M.; Haser, M.; Horn, H.; Kolmel, C. Chem. Phys. Lett. 1989, 162, 165.

(52) Matulis, D.; Rouzina, I.; Bloomfield, V. A. J. Mol. Biol. 2000, 296, 1053 .

(53) Wu, J.; Du, F.; Zhang, P.; Khan, I. A.; Chen, J.; Liang, Y. J. Inorg. Biochem. 2005, 99, 1145.

(54) Marcus, Y. Chem. Rev. 1988, 88, 1475.

(55) Gresh, N.; Šponer, J. E.; Spačková, N.; Leszczynski, J.; Šponer, J.

J. Phys. Chem. B 2003, 107, 8669.

(56) Gresh, N.; Šponer, J. J. Phys. Chem. B 1999, 103, 11415.

(57) Bouř, P.; Michalík, D.; Kapitán, J. J. Chem. Phys. 2005, 122, 144501.

(58) Bouř, P.; Keiderling, T. A. J. Chem. Phys. 2003, 119, 11253.

JP8058678 